\title{
Operation "Lifesaver": Canadian Atomic Culture 46| and Cold War Civil Defence
}

Frances Reilly, University of Alberta

On September 28th 1955, the city of Calgary executed one of the only major civil defence evacuation operations in Canadian history. The exercise, Operation "Lifesaver," was a product of careful planning over a series of months but failed to attract the interest of most Calgary citizens. The operation exhibited both the Canadian government's concern for civil defence during the 1950s and the desire for civic pride in a decade that favoured a homogenous and functional society. Operation "Lifesaver" was not an accurate representation of a nuclear attack; instead it was a controlled exercise devised to calm the fears of civilians in the face of possible war. Despite the rich primary sources available, Canada's civil defence experiences during the Cold War remain an allusive topic in Canadian historiography. Operation "Lifesaver" holds a prominent position in Alberta history in an era that defined much of Canada's nationality and society. This article is the third chapter of my History MA thesis which examines the place of Atomic Culture in Canadian history and the Canadian Cold War experience.

In September 1955, after months of careful planning and preparation on the part of the Canadian government and civil defence organizations, Calgary executed one of Canada's only major practice evacuations. The Calgary evacuation, Operation "Lifesaver," was a useful illustration of Canada's atomic era and a model which concretely captured the concerns and interests of the

\footnotetext{
Past Imperfect
14 [2008] | (C) |ISSN 1711-053X | elSSN 1718-4487
} 
age. Atomic culture is a term generally used to describe American popular culture surrounding the nuclear tests in the desert of the south-western United States during the 1950s. The mushroom cloud of the atomic era was a symbol of modern science and knowledge, power, and prosperity. This optimistic portrayal of nuclear innovation however stimulated fears concerning the destructive capacity associated with scientific technology which the media and government often used to their advantage by motivating civilians through controlled anxiety. The presence of the bomb in postwar society is not typically recognised as a Canadian Cold War experience except in terms of American cultural influence. The significance of Operation "Lifesaver" in Canadian history, therefore, is its demonstration of the nature of the Canadian Cold War experience in terms of the planers' solicitation of controlled anxiety to the civilians.

Operation "Lifesaver's" embodiment of atomic culture is evident through an examination of the planners' intentions, the project's portrayal, and the presentation of the operation's apparent success. Although presented to the civilian as a scientific experiment, the importance of Operation "Lifesaver" lay not within the civilian's impression of the exercise nor the practical value of an evacuation, but in the exercise's process, the official report's rhetoric, the topics of discussion between planners, and the prominent factor of aesthetics in the exercise itself. Based on the planning procedures, the general motivation behind the evacuation was propaganda and the effort to engage civilians and legitimize the civil defence exercise.

Over the past decade Canadian Cold War studies have expanded beyond the macro themes of military operations and political disagreements and have focussed on the more micro

Past Imperfect 
themes related to the individual. But while Canadian historians like Gary Kinsman, Valerie Korinek, and Franca Iacovetta have developed the scope of Canadian postwar history in terms of the individual's "cold war" within Canadian society in terms of gender, ethnicity, and ideology, Canadian Cold War studies still have yet to experience the marriage of the global view with the 48| individual's experience, or the psychological impact of the nuclear threat on the individual. Whereas American historians like Paul Boyer, Laura McEnaney, and Kenneth D. Rose look at the atomic bomb and the presence of nuclear science in the social mindset, Canadian historiography, with a few exceptions, has primarily shied away from the impact of military science and technology on the Cold War civilian. During the early Cold War the civilian was constantly aware of science and technology in society, whether as a threat like the nuclear bomb, or as a form of entertainment such as science fiction, or as a part of modern life as with domestic technology and medicine. Ideally, this article hopes to effectively demonstrate the existence of a Canadian atomic culture by analysing a civil defence exercise that, although presented in the form of a scientific experiment, catered to the concept of controlled anxiety.

Operation "Lifesaver" planners were not intent on replicating an actual attack. The Alberta Civil Defence Headquarters (ACDHQ) and Calgary municipality wanted Operation "Lifesaver" to be an artificial representation of nuclear warfare. In this way, Operation "Lifesaver" exhibited the difference between an exercise and a real threat which persisted throughout the Cold War. As historian Tracy C. Davis stated in her article "Between History and Event: Rehearsing Nuclear War Survival," "[t]he history of civil defense and its corollary, 
disaster, are deeply implicated in performance, pretense, and scripted pretexts." The Operation "Lifesaver" "performance" was a controlled scenario presented to a relatively apathetic public as a scientific experiment. The exercise was one of the primary pieces of concrete evidence demonstrating Canada's inclusion in the atomic age.

Operation "Lifesaver" was, more than anything, an effort to prove to Calgarians, Canadians, and the world at large, that western civilians could survive a nuclear attack. There are a number of possibilities as to why Calgary hosted the major civil defence exercise of Canada at this time. Calgary was the largest city in southern Alberta and, most importantly, a strategic location for oil and gas production, and an important centre for wheat distribution and meat packing. ${ }^{2}$ It was also "the Canadian gateway to rail traffic through the Rockies."3 Calgary was therefore considered a logistical target. But throughout the $1950 \mathrm{~s}$, and at the time of the exercise, Calgary was considered merely a secondary target. Another possibility of Operation "Lifesaver's" chosen location, therefore, could have been because the city was able to afford the production, planning, and execution of a major evacuation exercise. Finally, the most important aspect of the choice for Calgary was that it was an easy city to evacuate. Situated in the southern part of the province, surrounded by prairies, the city had numerous natural and unchallenged exits. The towns surrounding the city were also

\footnotetext{
${ }^{1}$ Tracy C. Davis, "Between History and Event: Rehearsing Nuclear War Survival" The Drama Review 46, 4 (Winter 2002), 40 .

2 Davis, 18.

${ }^{3}$ Ibid., 18-19.
}

Past Imperfect 14 [2008) | @ |ISSN 1711-053X| elSSN 1718-4487 
available as receiving communities in the event of an evacuation. Had the planners used a primary target city like Vancouver, a city wedged between the coastal mountains and the Pacific Ocean and whose civilians were limited to one exit route, the practice would have been decidedly different, taking on a completely different objective. A Vancouver evacuation, in the most simplest of $50 \mid$ terms, was not aesthetically pleasing. Calgary, on the other hand, offered the possibility of a direct and uncomplicated exit which, in turn, planners could use to their advantage when trying to sell the concept of civil defence to the public.

Planners expected Operation "Lifesaver" to symbolise not just Alberta's preparedness in the event of an attack, or even Canada's, but of the western world's readiness. Director of civil defence, Geoffrey Bell wrote in his preliminary notice which announced the exercise that,

Civil Defence in Calgary, through me, promises you at the cost of much hard work - its very best services. In return it begs for your co-operation always - but especially on Wednesday, September $21^{\text {st }}$, when the eyes of the whole of North America will be focussed on us. ${ }^{4}$

Operation "Lifesaver" was a political exercise in the form of a science experiment that sought more than to test the reactions of civilians of a city under simulated attack. The exercise was a tool of propaganda formed by civic pride and images of western might,

\footnotetext{
${ }^{4}$ Geoffrey Bell, "City of Calgary Civil Defence Evacuation Exercise: Preliminary Notice," April 1955, in Report on Operation Lifesaver (February 20, 1956), 51, Civil Defence, “Department of Transportation,” acc. No. 85.368, Provincial Archives of Alberta, Edmonton. 
and it was created in an effort to encourage Canadians to believe that they could survive a nuclear attack.

Operation "Lifesaver" was not the only large-scale civil defence practice during the Cold War. It was, however, the most elaborate civil defence practice of its kind in Canada: "The scale of the plan was unprecedented and it attracted international attention. NATO decided to send observers." practices preparing the Canadian civilians and government for nuclear war, Operation "Lifesaver" involved the direct participation of residents. Civil defence, therefore, moved beyond the hypothetical assumptions of the government's reaction to the possibility of nuclear war, and away from a purely theoretical situation. This is not to say that Operation "Lifesaver" was the only civil defence practice which involved the active roles of civilians: Operation "Dogwood" a year later, for instance, involved the participation of civilians in a planned hospital evacuation in Vancouver. ${ }^{6}$ The majority of tests during the 1950 s were, however, based on abstract situations dealt with in theoretical manners. One such example was the Alert I exercise in the winter of 1954 and 1955. Alert I was a civil defence practice presented in the form of a war game. Headquarters, chosen at the beginning of the game, established strategic plans based on given scenarios. The exercise did not even take place in real time but was sped up to "eliminate lags." 7 The staff training

\footnotetext{
${ }^{5}$ Randy Richmond and Tom Villemaire, Colossal Canadian Failures 2: A Short History of Things That Seemed Like a Good Idea at the Time (Toronto: The Dundurn Group, 2006), 90-1.

'(No Interviewer/Announcer), "CBC Newsmagazine" $<$ http://archives.cbc.ca/IDCC-1-71-274-1472/conflict_war /cold_war/> November 25, 1956 [accessed December 3, 2007].

${ }^{7}$ G.R. Howsam, letter, 1954, acc. no. 85.368, PAA.

$$
\begin{gathered}
\text { Past Imperfect } \\
14 \text { [2008] | () |ISSN 1711-053X | elSSN 1718-4487 }
\end{gathered}
$$
}


plan, as issued by coordinator G.R. Howsam to the Committee Chairmen of the ACDHQ staff, detailed the exercise training sessions. According to a letter from Howsam, the exercise was to begin on November 2, 1954 with the appointment of community representatives. The first training session would take place on November 30, and the first Tuesday of each month leading up to 52) this point would be devoted to training.

Alert I included fifteen municipalities around Alberta: Calgary, Camrose, Grande Prairie, Leduc, Lethbridge, Medicine Hat, Peace River, Ponoka, Red Deer, Rocky Mountain House, Strathcona, Vulcan, Westlock, Northern Mutual Aid Area, and Central Mutual Aid Area. ${ }^{8}$ The two Mutual Aid Areas were apparently a combined effort of communities to help the situation in Edmonton which was, judging from the layout of the plan, dire. As the province's capital city, and as a strategic bomb target, Edmonton was the primary focus of the theoretical attack. The rest of the exercise was built around the plight of Edmonton and the duties of the rest of the province to keep the capital city functional. The Mutual Aid Areas were to provide the capital city with rescue facilities, equipment and supplies, utility and works projects, auxiliary officers, and firefighters. ${ }^{9}$ The headquarters for the experiment provided the fifteen municipalities each with a scenario concerning damages inflicted on their respective areas. The community representatives would then have to devise a civil defence and post-attack reconstruction plan to deal with the disaster by the close of the exercise.

\footnotetext{
${ }^{8}$ Development of Exercise 'Alert I,' 1954, acc. no. 85.368, PAA.

${ }^{9}$ Ibid. 
The level of destruction differed between the communities. Calgary, according to the exercise, suffered from four two-thousand pound "H.E." [high explosive] bombs; two landing on residential districts, one destroying the Langevin bridge and demolishing long distance phone cables, and one hitting the C.P.R. yards "causing complete disruption of service north, east, and south of City." 10 Calgary therefore would have to deal with transportation difficulties, communication failures, and the destruction of service routes. Grande Prairie, meanwhile, would suffer four hundred one-kilo incendiaries, Leduc would have one "U.X.B." [unexploded bomb] a mile north of the community, and Red Deer would experience one two-thousand pound "H.E." bomb which would damage the town's road bridge beyond repair, resulting in numerous casualties and property damage. No advice, oddly enough, was offered regarding the possibility of nuclear attack.

The representatives of the communities then devised methods to deal with their disasters. There was a variety of responses. At the close of the exercise the Calgary representatives had dealt with their problems: the residential incidents were under control with the hospitalization of the casualties, the re-housing of the displaced, and the restoration of utilities. Traffic was rerouted around the demolished bridge, teams were clearing up the debris around Calgary, and although the rail traffic remained disrupted, restoration was estimated to take place within the next twenty-four hours. Additionally, Calgary was preparing to receive ten thousand displaced persons from

\footnotetext{
${ }^{10}$ Ibid.
} 
Edmonton. ${ }^{11}$ Grande Prairie, on the other hand, failed to report its action plan or situation at the close of the exercise. Leduc positioned a guard at the "U.X.B." Military Command in Edmonton and dispatched a disposal squad. In Red Deer, traffic was rerouted around the destroyed bridge and arrangements were being made to plank the bridge for wheeled traffic. The city was 54 also preparing to receive one thousand displaced persons and three-hundred seriously injured individuals from Edmonton. ${ }^{12}$ The Alert I exercise attempted to presuppose and prepare for the likely situations presented by an enemy attack. The process of dealing with the hypothetical attack was itself purely theoretical; Alert I was nothing more than a game in strategy. Operation "Lifesaver," in contrast, presented civilians with an active exercise responding to the nuclear threat. Planners moved from two-dimensional maps to a three-dimensional city, and replaced tokens with civilians. But although Operation "Lifesaver" developed from the planning room, it remained a very controlled experiment focussing on the logistics of a potential attack rather than the threat.

The plan for a massive civilian evacuation out of Calgary was introduced publicly on February 11, 1955. Provincial Secretary-Treasurer, C.E. Gerhart, Federal Civil Defence Coordinator, F.F. Worthington, and National Health and Welfare Minister, Paul Martin were behind its conception. The plan relied on input from the mayor of Calgary, Don MacKay, Director of Civil Defence, Geoffrey Bell, and Coordinator for Operation "Lifesaver," G.R. Howsam. The evacuation was scheduled for

\footnotetext{
${ }^{11}$ Ibid.

12 Ibid.
}

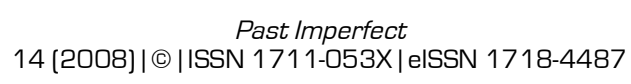


Wednesday, September 21, 1955 and intended to engage the movement of 40,000 Calgarians, one quarter of the city's population. ${ }^{13}$ Because of heavy snows, however, civil defence planners in Calgary decided to postpone the exercise for a week and, as a result, approximately only 6,000 residents participated. ${ }^{14}$ On September 28, 1955 at 10:50 a.m., a time which remained unknown to the participants to better simulate a

surprise attack, the mayor of Calgary set off the warning signal to notify the selected population within the city to prepare for their evacuation to surrounding communities. ${ }^{15}$ As a contemporary CBC documentary stated:

School children were all told to go straight home as fast as they could. Housewives left their chores. Businesses closed down. Men took their cars home, collected their families, took food and clothing for one whole day, and made for routes out of town already organized and cleared by the police in conjunction with city and provincial organizers. ${ }^{16}$

At 1:00 p.m. after the residents had "escaped," the RCAF conducted a simulated attack over the north-eastern part of the city where the participants of the exercise lived. ${ }^{17}$ To better

${ }^{13}$ Richmond and Villemaire, 90.

${ }^{14}$ Report on Operation Lifesaver, 19, acc. no. 85.368, PAA.

15 "The time at which the operation would commence was kept secret but Civil Defence personnel were ordered to be at their action stations by 1000 hours. The Warning Yellow was disseminated from ACDHQ in Edmonton over Alberta Government Telephones at 1032 hours. The Alert was sounded on the Calgary sirens at 1050 hours." Report on Operation Lifesaver, 14.

${ }^{16}$ (No Interviewer/Announcer) "CBC Newsmagazine,"

$<$ http://archives.cbc.ca/IDC-1-71-274-1461/conflict_war/cold

_war/clip2>, October 9, 1955 [accessed December 3, 2007].

${ }^{17}$ This "attack" basically consisted of a flight over the city.

$$
\begin{gathered}
\text { Past Imperfect } \\
14 \text { [2008] | (c) |ISSN 1711-053X | elSSN 1718-4487 }
\end{gathered}
$$


conduct the exercise in an orderly and controlled fashion, Operation "Lifesaver" converted the drill hall of the RCAF Station Calgary into a "war room" decorated with wall maps of the city and receiving communities, as well as a communications board following the movement of the evacuees out of the city. Military personnel and civil defence observers, switch board 56| operators, and clerks helped run the program from the station. ${ }^{18}$ Meanwhile, "Bell and other civil defence leaders [directed] the exercise in a bomb proof bunker built at the municipal golf course at a cost of $\$ 70,000 . " 19$ Television crews followed the course of the exercise from the control station to the deserted streets in the suburbs in north-eastern Calgary, to the families making their way to the receiving communities surrounding the city. The scientific experiment, fully recorded, stressed the importance of civil defence and order in the face of chaos to civilians across the country.

\section{Scientific Method and Preparation for the Experiment:}

Operation "Lifesaver" was a scientific experiment in many ways; it featured a method, subjects and materials to be used in the test, and expected results. And, like a scientific experiment, the exercise followed the universal steps of an investigation: first, the formulation of a hypothesis: if Calgary residents leave Calgary in an orderly fashion, they will save themselves from a nuclear attack; second, a selected research method and design study: observation of the evacuation through film and data; collection

\footnotetext{
${ }^{18}$ Richmond and Villemaire, 91.

${ }^{19}$ Ibid.

Past Imperfect

14 [2008) | ( ) |ISSN 1711-053X | elSSN 1718-4487
} 
and analysis of the "empirical evidence": compiled mainly by the media and the ACDHQ; and a report depicting the findings.

The Central Mutual Aid Area (CMAA), the area selected by the ACDHQ, was primarily a suburban section of the city and it featured well organized routes which would be easily traversed in the event of an emergency. The decision to use the population from this area of the city had many benefits which, although not openly discussed by the planning committee, were most likely behind the selection of the north-eastern section of Calgary. The suburb, as opposed to the inner city, was easy to evacuate, but there was also the issue of residents. The suburb housed the middle-class citizens, those most likely to cooperate in an organised evacuation and, most importantly, have the means of transportation to participate in an evacuation. Driving through the organized and open streets of suburbia, the residents of the north-eastern section of Calgary were expected to complete a clean and well-ordered exit while the rest of the nation watched. The north-east section of Calgary, as depicted in the map below, was divided into twenty-one zones for the course of Operation Lifesaver. 


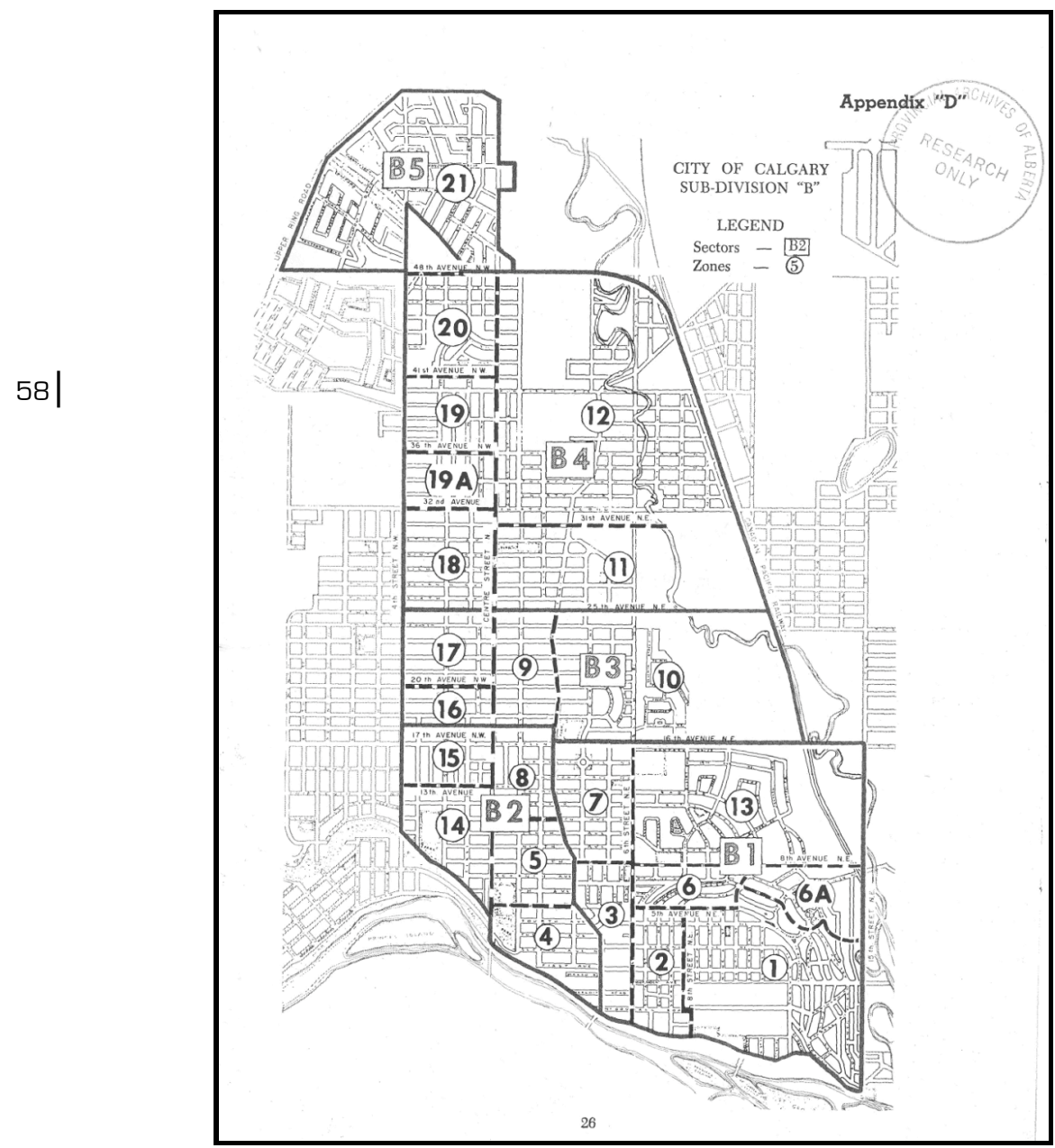

Report on Operation Lifesaver, “Appendix,” 26.

The residents of each zone were issued directions to a different receiving community outside of the city. These routes and communities were colour coded and corresponded to the location of the evacuee's neighbourhood. The participants of the exercise, as is wont with subjects of most scientific experiments, were to be

Past Imperfect

14 [2008] | (C) |ISSN 1711-053X | eISSN 1718-4487 
reimbursed for their troubles: they were paid for the day missed from work and "insurance coverage was arranged for participants who might get in a car accident or sustain property damage during the exercise." 20

Even prior to the experiment, the ACDHQ studied its subjects with a series of questionnaires. Although participation to the exercise appears to have been voluntary on the part of the civilian the selection process conducted through the questionnaires apparently focussed on achieving a particularly cooperative group that would be enable for a smooth display of civil preparedness. The intent of the tests was not entirely clear; the tests could have been designed to benefit the exercise by providing the planners with information to be extrapolated in a real life event but they could have also been designed to make the exercise run more smoothly through a selection of capable, mobile, and willing individuals. Along with the extensive information regarding the destination points of the exercise, the Operation "Lifesaver" coordinators also questioned residents about their family status and on their abilities to travel. In one specific questionnaire, sent months prior to the exercise, the ACDHQ obtained information concerning the number of members within the participating families, the number who were at home during the day, and the ages of the children of the family. Potential participants were also questioned about their cars: did they have a serviceable car and if so how many people could it hold and what was its availability? Finally, the ACDHQ wished to know "[d]etails of any members of family who by reason of infirmity, etc. would be incapable of joining in an Evacuation

${ }^{20}$ Richmond and Villemaire, 91.

Past Imperfect

14 [2008) | @ |ISSN 1711-053X| elSSN 1718-4487 
Exercise." ${ }^{21}$ The bottom of the questionnaire provided space for the civil defence warden of the area to include remarks and a signature. Following this form, approved CMAA families received, in June 1955, a form stating that "It has been noted from the Warden's Canvass that your family will take part in the Exercise" and the resident would either "evacuate your family in 60| your own car" or would find transportation at fixed assembly points within the community. ${ }^{22}$ With this form, the resident was a classified participant of the controlled experiment.

The study's emphasis on individual transportation indicated the nature of Operation "Lifesaver's" primary intent to provide civilians with a comforting image of survival. Civil defence, by stressing the importance of personal means of evacuation, fed the post-war capitalist mentality which associated freedom with the self and consumerism. Of course, in addition to the image of the individual escape ACDHQ made plans for residents without means of transportation: busses would collect passengers at pre-arranged assembly points and residents were urged to notify neighbours ahead of time if they were in need of transportation. A mass evacuation would have been more practical in terms of cost and logistics had it focussed on public transportation for the entire population. But the ability to drive away from danger satisfied the individual's hunger for self control, and communal assembly points and public transportation were reminiscent of communism. The evacuation plan, although more communal in theory than the fallout shelter which was based on the idea that the civilians would literally buy their own personal

\footnotetext{
${ }^{21}$ Report on Operation Lifesaver, "Appendix."

${ }^{22}$ Ibid. 
freedom to put in their backyards, was in fact just as capitalist in practice. In the era of the individual and capitalism, to consume was to survive; a family car and a full tank of gas could spell safety from attack and there was no need to depend on anyone else. And so the exercise had its choice of participants, suburban civilians who would complete a well-ordered exit from the city. The motivation tactics of the exercise moved away from the comfort of the suburb and into the terrifying possibilities of nuclear warfare through the application of controlled anxiety.

In April 1955, Howsam issued a preliminary notice to Calgary residents regarding the impending civil defence evacuation exercise. The rhetoric of the notice, along with other sources that supported the exercise, such as the local newspaper, attempted to combat all possibilities of civilian apathy towards civil defence programs. The Herald then pulled out all the stops to persuade people to participate. A front-page column by a reporter who had witnessed the devastation of Pearl Harbour warned Calgarians that they were not invulnerable from an attack. The Herald editorial the day before the exercise proclaimed it "the plain duty of every responsible citizen to co-operate as fully as possible. ${ }^{23}$

The notice also included brief references to the possibility of a hydrogen bomb dropping on Calgary:

The Federal Government - with all the very latest intelligence reports in its possession - is satisfied that, if war ever comes, the "H" Bomb will be used. (You and I may have our own ideas about this - but I think we have got to admit that, based as they probably are

\footnotetext{
${ }^{23}$ Richmond and Villemaire, 93

Past Imperfect
14 [2008) | (C) |ISSN 1711-053X| elSSN 1718-4487
} 
on nothing better than wishful thinking, they are not worth a great deal.) $)^{24}$

With an apparent frankness and voice of reason, Howsam used this statement to work against the civilian cynicism towards civil defence. The notice used the superior knowledge and understanding of the government as a reference point and reason to follow a civil defence program. Bell's notice ended with the following explosive and fear-inducing statement:

\section{THE ONLY WAY OF ESCAPING CERTAIN DEATH WHEN ONE OF THESE THINGS EXPLODES IS TO BE AT A SAFE DISTANCE FROM THE AREA OF EXPLOSION.}

You and I, therefore, have just two choices - and as this is a free country - we may take which one of them we fancy and no one can force us to do otherwise. We can stay in the target area and die - or we can evacuate ourselves and live. It must be one or the other - and the choice is in our hands. ${ }^{25}$

The warning clearly defined what was apparently common sense: there was going to be a nuclear war and the best way to avoid getting killed was to evacuate the city when the siren rang. The statement was almost too simplistic in nature to be manipulative, particularly with its blatant reference to the free western world: "this is a free country." Perhaps this message was not so much a fear tactic as an attempt to cast civil defence as a natural response to the global issues at hand and the attractive qualities of

\footnotetext{
${ }^{24}$ Report on Operation Lifesaver, "City of Calgary Civil Defence Evacuation Exercise: Preliminary Notice," 51.

${ }^{25}$ Ibid (Original emphasis).

Past Imperfect
14 [2008] | (C) |ISSN 1711-053X | eISSN 1718-4487
} 
participating in the evacuation exercise. The message was also personal; its authoritative and advising tone was masked by a sense of confidentiality with the addition of the first person, "I," and the second person, "you." Manipulation and fear tactics were not the only methods of making Operation "Lifesaver" appeal to the Calgary resident; constructive imagery was equally important. Civil defence had to be driven by more than fear - it had to appear attractive to the civilian.

The planning procedures for Operation "Lifesaver" were elaborate in their attempts to maintain an element of surprise for the participants and also to achieve a level of safe control throughout the exercise. The Movement Control Committee was an organization involved in the planning process which regarded a variety of plans by the government and the ACDHQ and which discussed the organized evacuation of Calgarians to surrounding areas. The minutes from the Movement Control Committee meeting which took place on June 20, 1955, detailed the various concerns of the exercise's operators. ${ }^{26}$ Included in the minutes were the following subjects of discussion: "Details of the problem," which regarded the geographical route of the evacuation and how to avoid bottlenecks on the highways and escape routes; "Control organization required," concerning the use of municipal and federal police officers to direct the routes; "Communications," which looked at how best to control the situation, namely proper signage of escape routes to relay information to the drivers and to introduce alternative routes in the event of any difficulties; "Administration Aspects," regarding

\footnotetext{
${ }^{26}$ Movement Control Committee [Operation Lifesaver], "Meeting Agenda," June 20, 1955, acc. no. 85.368.

Past Imperfect 14 [2008) | @ |ISSN 1711-053X| elSSN 1718-4487
} 
signs, auxiliary police and civil defence personnel identification and also the power of the civil defence auxiliary police; "Return," the timing and the road signs for the route back, and where the evacuees should go upon their arrival in Calgary; and, finally, "Trial run."27 Following these topics was a discussion regarding the plan to close the highways leaving Calgary for the amount of 64 time it took for evacuees to leave the city. Mixed with this effort to maintain order in a potentially chaotic situation was the desire for an element of reality and surprise, which turned out to be more artificial than anything else:

It was agreed that in order to maintain the element of surprise for the evacuees that the public be informed by means of press and radio, by the Dept. of Highways, that the highways being used for the evacuation would be subject to closure in sections for periods up to three hours (this period may be four hours, but the actual length of time will be worked out) during the time 1000 to 2000 hours on the $21^{\text {st }}$ of September. $^{28}$

The committee also discussed the waves of civilian departures from the city according to the destinations' distances:

Sgt. Cunningham stated that the RCMP would be pulling in their people from all over the province for traffic control duties during the exercise and that with the assistance given by Western Command he saw no difficulty whatsoever in traffic control. ${ }^{29}$

\footnotetext{
${ }^{27}$ Ibid.

${ }^{28}$ Ibid., "Minutes from the Movement Control Committee for Operation "Lifesaver"'

${ }^{29}$ Ibid. 
A letter from Bell suggested the publication of a notice regarding the transportation issue of the evacuation process. The notice outlined, in addition to introducing the routes and the preparatory procedures that the Calgary evacuee should take before the exercise, the possible hazards to highway travel at the time of the evacuation. Bell suggested the time when the routes should be blocked in accordance with the exercise:

To facilitate the movement of motor traffic taking part in this exercise, it will be necessary to close certain Sections of the Highways mentioned hereunder for periods of about 2 to 3 hours at some time between $1000 \mathrm{hrs}$. and $1700 \mathrm{hrs}$. on Wednesday, $21^{\text {st }}$ September, 1955. [...] The closure will affect all traffic on these highways moving in the direction of Calgary and it will be imposed in the Sections concerned without further notice. ${ }^{30}$

Blocked traffic and controlled routes were features of peacetime; neither of these aspects would occur in the event of an actual evacuation. But then, this was not an actual evacuation.

A level of communication between planner and evacuee was integral for a successful execution of Operation "Lifesaver." The signs colour-coding the escape routes provided were also a subject hotly discussed by planners:

It was, you will recollect, agreed that the signs should be 8 feet $\mathrm{x} 4$ feet, white background, with black lettering in the top half and the route colouring in the bottom half. The size [was] regarded as absolutely necessary by those people at the Conference with

\footnotetext{
${ }^{30}$ G.O. Bell, letter, July 5, 1955, Emergency Measures Organization, "Executive Council," acc. no. 76.428 , PAA.

Past Imperfect 14 [2008] | (C) |ISSN 1711-053X | eISSN 1718-4487
} 
much experience of traffic direction and control; it has the further merit of allowing us to utilize sheets of ply-wood in their normal size. ${ }^{31}$

The nature of the communication used by the city planners were visually positive; reminiscent of elementary school orientations, the coloured signs created a sense of easily comprehendible 66| directions as well as comfort in what would be a stressful and frightening time for most civilians. The six escape routes from Calgary to the receiving communities were symbolised by the colours pink, light blue, light green, brown, yellow, and red. ${ }^{32}$ Pink was used for those residents destined for Airdrie and Crossfield (leaving Calgary by $4^{\text {th }}$ Street N.W. and Centre Street N.W.), while light blue was for those destined for Carstairs, Didsbury, Olds, Bowden, Innisfail, and Penhold (using Edmonton Trail). Light green marked the route for evacuees destined for Carbon and Drumheller (travelling along $16^{\text {th }}$ Avenue N.E., the Trans-Canada and No. 9 Highway) and brown was originally for those destined for Irricana and Beiseker (leaving by $16^{\text {th }}$ Avenue N.E. and the Trans-Canada), although according to the plans, there appeared to have been a change, either with the destination point or the route. Yellow marked the route to Acme, Three Hills, and Trochu (the residents would travel by $16^{\text {th }}$ Avenue N.E., the Trans-Canada, No.9 Highway and No. 21 Highway) and red designated the route to Strathmore and Rockyford (by $8^{\text {th }}$ Avenue N.E., Riverside Boulevard, Blackfoot Trail, and No. 1 Highway). ${ }^{33}$

\footnotetext{
${ }^{31}$ Bell, letter, June 30, 1955, acc. no. 76.428, PAA.

32 Ibid.

${ }^{33}$ Ibid.
} 


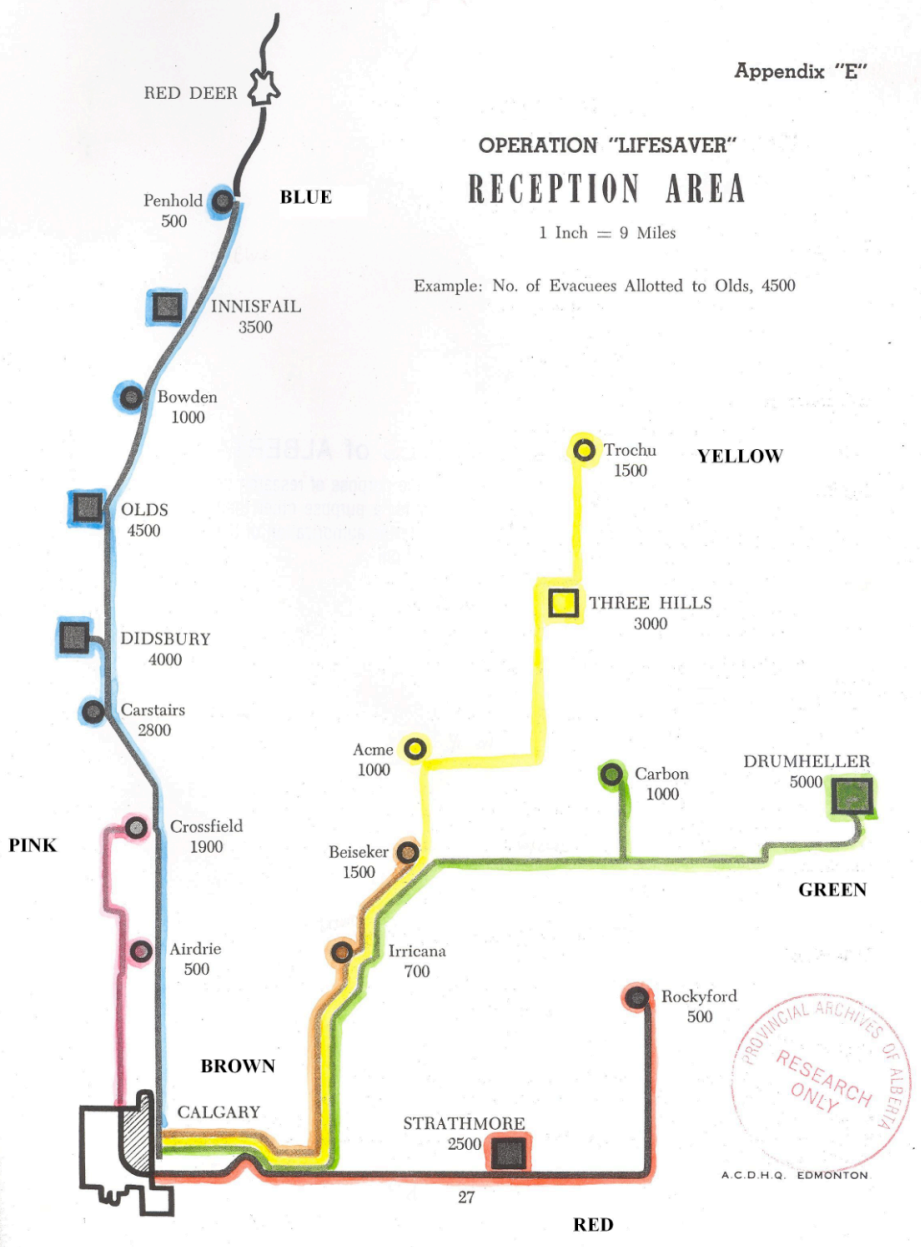

Report on Operation Lifesaver, “Appendix," 27.

The report did not fully discus whether or not the signs were to remain on the roads following the practice in preparation for an actual attack or, for that matter, what would be done with them following the experiment. Nor was there any apparent fear of enemy infiltration into the civilian escape plan. The primary

Past Imperfect

14 [2008] | ( ) |ISSN 1711-053X | eISSN 1718-4487 
concern of planners appeared to be nothing more than the efficiency of providing the participant of the exercise with a clear portrayal of an escape route.

\section{Image:}

68| Image was a primary factor of atomic culture. Historian Valerie Korinek has studied the image of postwar prosperity and related superficial representations of Canadian suburban life during the 1950s while others, like American sociologist Guy Oakes, have examined the image of the Cold War in civil defence. The messages expressed by images throughout the planning process's images best characterised the intent of Calgary's Operation "Lifesaver." The issue of image remained prevalent throughout a long and drawn-out discussion regarding the division of funds for the civil defence operation in a series of letters between Bell and Howsam beginning in October 1954. Central to this discussion was the power of images to enforce civic pride. The insignia on the shoulder and beret badges worn by civil defence officers emphasized the apparent concern for a prominent Calgary presence in the project. Bell expressed the importance of image in a letter to Howsam, dated March 14, 1955:

[...] I feel that a shoulder title simply indicating 'Canadian Civil Defence' would lack everything required to fire local imagination. I feel that the combination set out above, showing that the wearer belongs to the Calgary unit of the Alberta Corps of Canadian Civil Defence will go a long way towards building up an esprit de corps which we shall want to

\footnotetext{
Past Imperfect

14 [2008) |@ |ISSN 1711-053X| elSSN 1718-4487
} 
establish. It will also make it easy for re-enforcement to be readily identified. ${ }^{34}$

Civil defence in this case was more of a pre-war operation rather than one concerning post-war disaster. The insignia's importance was not so much for identification of the officer in the chaos of a post-attack city, but the identification of Calgary's readiness for a post-attack situation. The crest was to attract the public's attention, to create an awareness of the force and power of civil defence in Calgary, and the city's progressive movement towards a united operation.

A couple months later on May 9, Bell wrote to Howsam again, this time expressing his desire to have the civil defence officer uniforms sooner than September. Bell wanted the uniforms to appear as a contingent in the Calgary Stampede procession which would take place in July:

My Controllers and I feel this is an opportunity not to be missed, this year, of showing a live Civil Defence organization off to thousands of people, from Calgary and elsewhere, who will be lining the route, but it means that a decision on the question of badges MUST now reach me without delay. ${ }^{35}$

The element of civic pride in the civil defence preparations in Calgary was accentuated by a June 14 letter to Howsam from another organizer by the name of A. Pert. Pert's letter regarded the influx of local auxiliary civil defence police which would be recruited and trained for the September exercise. His letter

\footnotetext{
${ }^{34}$ Bell, letter to G.R. Howsam, March 14, 1955, acc. no. 76.428, PAA.

${ }^{35}$ Bell, letter, May 9, 1955, acc. no. 72.428. 
addressed the urgent need and importance of the availability, and production, of 150 civil defence uniforms. Once again, the importance of the uniforms was based on image and the symbol of civic might, rather than their utility for the pending attack:

It appears to be generally considered that these men who are giving their time and a good deal of interest to training for this work, feel that a distinctive and suitable police uniform will be necessary if they are to operate efficiently. It is also suggested that without such a uniform it will be very difficult to maintain the interest and co-operation of these people. ${ }^{36}$

Pert's ending comment regarding the importance of maintaining the interest of "these people" is particularly compelling in its apparent elusiveness. He could have been referring to the auxiliary officers. If this were the case it would be because of the officers' lack of interest in the practice, which would emerge from their lack of a powerful image in the eyes of the public. More likely, Pert was referring to the civilians participating in the exercise. If this were the case, what he was referring to was the common fear of civilian apathy in the face of post-attack planning. Apathy generally leads to panic in the event of chaos because of lack of preparation, both mentally and physically, for disaster. ${ }^{37}$ Essentially, Pert and other planners noted that if

\footnotetext{
${ }^{36}$ A. Pert, letter to G.R. Howsam, June 14, 1955, acc. no. 76.428.

${ }^{37}$ In her book Panic Diaries, American sociologist Jackie Orr examined the impact of panic on the public, or what she calls the "group mind." She discussed the effect of "suggestion" on the public's perspective (using both civil defence and Orson Wells's 1938 broadcast of War of the Worlds) and how this could, through the proper application of authoritative management, control the public's reaction to a stimulus. Orr, Jackie. Panic Diaries: A Genealogy of Panic Disorder (Durham and London: Duke University Press, 2006)43-4.
}

\author{
Past Imperfect \\ 14 [2008) | (C) |ISSN 1711-053X | elSSN 1718-4487
}


civilians were not prepared to accept the possibility of nuclear attack in the event of a war they would be lost in the chaos. Pert presented the civil defence officer uniform as a tool to prepare civilians for attack and to give them a sense of security following an attack. In pre-attack society the uniform would indicate to the civilian that there was a possibility for war and therefore reason to prepare. The uniform also indicated that the civilian's city, province, and nation were not prepared to buckle under an enemy attack. In post-attack society the uniform would be both a symbol of surviving western society and a tool to steer the traumatized civilian towards the familiarity of social order, law, and society.

The civilian was the central character in the event of a nuclear war: the civilian was the target and the civilian was responsible for maintaining the continuation of its society and culture in the face of a nuclear holocaust. Through the image of power and authority, the uniform's symbolic value would spurn the apathetic civilian into activity. Pride was behind Pert's concern for the civil defence officer's representation, but there was also a strategic quality to it in terms of communication; the uniform would keep civilians civilized, even in the chaotic aftermath of a nuclear bomb. Visual communication through icons and symbols were central to the effort of re-orientation following a disaster. Physician J.S. Tyhurst, in his 1954 report on the psychological effects of a nuclear war on the civilian, looked at the importance of communication which lay not only with technology, such as telephone, radio, and television, but with institutions and institutional symbols. First Aid and Red Cross 
symbols, for instance, were forms of communication and should therefore be strategically placed in the event of an emergency or disaster. The re-establishment of the familiar, "the reidentification of individuals as people and as social roles, and the early reconstruction of basic social groupings (e.g., the family, the work group) are essential features for the process of recovery." 38 72| In times of stress, Tyhurst continued, institutional symbols assume "added meaning:"

One should recognize the communication value of the first-aid sign, the badge, the armband, the uniform, and the red-cross. Such symbols have very strong connotations, should not be used indiscriminately but strategically to ensure their maximum effect for information and reassurance. ${ }^{39}$

The question remains, however, would the wounded civilian really care whether he or she was being aided by a Civil Defence officer of Canada, or of Alberta, or of Calgary? The significance of the badge in this case, remained in the pre-war phase which held civil defence as a symbol of civic strength, rather than of helpful communication in the chaotic aftermath of a nuclear attack.

\section{Publicity:}

Publicity was also particularly important to the meaning of Operation "Lifesaver." The official Operation "Lifesaver" report, compiled by the ACDHQ and published in early 1956,

\footnotetext{
${ }^{38}$ J.S. Tyhurst (MD), Psychological and Social Consequences of Disaster “What Should the Doctor Do?" (Montreal and Ottawa: Department of Psychology, McGill University, and the Defence Research Board, 1954), 21.

${ }^{39}$ Ibid.
}

$$
\begin{gathered}
\text { Past Imperfect } \\
14 \text { (2008) | (C) |ISSN 1711-053X | elSSN 1718-4487 }
\end{gathered}
$$


emphasized the importance of communications and technology on the overall effect of the study:

Interest in Civil Defence was greatly stimulated in Alberta due to the preparations for and during the actual Exercise. For this we must give great credit to the press, radio and TV companies and their representatives. They were generous in their assistance with publicity, and the reporting and recording by their representatives showed a wellinformed knowledge of Civil Defence which resulted in accurate and instructive publicity. ${ }^{40}$

An Alberta civil defence newsletter, the Civil Defence Circular recognized, in an issue devoted exclusively to Operation "Lifesaver," the wide scale media coverage of the exercise which included The Calgary Herald, The Albertan, Canadian Press, British United Press, radio stations such as C.F.A.C., C.F.C.N., and C.K.X.L., C.H.C.T. - TV, Federal Civil Defence Information Service, National Film Board, Associated Screen News, C.B.C. radio and television, Saturday Evening Post, Maclean's, Winnipeg Free Press, Montreal Star, Toronto Telegram, Time Magazine, Vancouver Sun, and the Department of Economic Affairs. ${ }^{41}$ A $\mathrm{CBC}$ television documentary featuring Operation "Lifesaver" presented the exercise in a heroic fashion, adding a sense of drama with the incidental music which played throughout the program. The documentary followed the events of the practice from the initial alarm, to the journey out of the city, to the lunch for evacuees in the receiving communities, and, finally, the return home.

${ }^{40}$ Report on Operation Lifesaver, 22.

${ }^{41}$ Civil Defence Circular 5, no. 7, October 15, 1955, acc. no. 85.368. 
This course of events was followed through a specific but anonymous family: it first showed the housewife of the family in the suburban kitchen hearing the civil defence warning via the radio, then her children running home from school, and finally her husband leaving his job in town for home. The documentary showed the process of emptying the city and the work of 74| programmers at the civil defence control centre in Calgary. The receiving communities were portrayed as welcoming and cheerful towns with groups of friendly volunteers providing a warm lunch for the "refugees." The documentary noted that " $[\mathrm{t}]$ hough the weather was chilly, it was dry and most evacuees enjoyed their day in the country." 42 In addition to stressing the positive aspects of the practice, the $\mathrm{CBC}$ program accentuated the importance of the exercise with the exuberant ending statement: "Operation 'Lifesaver' has set the pattern for Canadian civil defence. War may never come, but if it does it will be a city with a plan whose citizens will survive."43 The announcer also noted that Operation "Lifesaver" was a controlled practice but that, "if the real thing ever comes, people will remember the practice and follow the routine." 44 The documentary provided the general intent of the experiment: to achieve attention, not to create awareness. In this way, publicity was a primary component of Operation "Lifesaver."

The ACDHQ Operation "Lifesaver" report detailed the course of the civil defence practice. In many ways, the ACDHQ report was a manner of scrap book: it included responses to the course of events by the main programmers, timetables, maps of

42 “CBC New smagazine,” clip 2, October 9, 1955.

${ }^{43}$ Ibid.

${ }^{44}$ Ibid. 
Calgary and of the surrounding and participating communities, and the various documents issued to the public concerning the practice. The report, however, contained no photographs of the exercise nor of any other aspect of Operation "Lifesaver," with the exception of an aerial photograph of Calgary taken the morning of September 28, 1955. The physical attributes of the practice were converted into a theatrical response to the perceived nuclear threat. The report, with its lack of photographic evidence of the events which took place on September 28, was no more real than many of the presupposed events found in civil defence handbooks and government reports concerning postwar reconstruction activities. In this way, the report could be considered a contrived representation of an apparently realistic event.

The official report portrayed Operation "Lifesaver" as a satisfactory success:

Exercise "Lifesaver" was of great value. Despite the difficulties and the disappointments - and there were many - it paid valuable dividends. For example the existing civil defence organization was given a good test, and its strength and weakness under operational conditions were brought out. Also it provided practical field training at all levels of government, and created new interest in civil defence both in rural and civic areas by giving the people a definite job to do. ${ }^{45}$

According to the report, participants respected authority and cooperated with the plans issued by the ACDHQ. As with most

\footnotetext{
${ }^{45}$ Report on Operation Lifesaver, Introduction by Howsam.
} 
observational methods of research, the Operation "Lifesaver" experiment was subject to bias. Reports following the exercise, in the ACDHQ booklet, in the newspaper, and in civil defence newsletters, emphasized the cooperation of civilians, and their eagerness to join in the activities:

Most evacuees displayed keenness and enthusiasm for the Exercise. Of those questioned none voiced any complaint regarding expense, encroachment on their leisure or leaving their homes unoccupied. The attitude of those who refused to take part in the Exercise was disinterest, disbelief, or distrust in the Exercise, and cynicism, or they offered some excuse that the Exercise did not concern them. The attitude of pedestrians who walked to assembly points was excellent." 46

The exercise apparently achieved the purpose of the project, which was detailed at the beginning of the report:

Operation "Lifesaver" was a co-operative civil defence project between federal, provincial and municipal authorities and was designed to ascertain some of the problems that would be faced by cities such as Calgary when evacuating large groups of people from a threatened area. The exercise was also designed to test civil defence organization and training in many of its branches, at the provincial, C.M.A.A. and municipal levels. ${ }^{47}$

By focussing on the exercise's success and significance to the world of civil defence, the report maintained the enthusiasm that

${ }^{46}$ Ibid, 22.

${ }^{47}$ Ibid, "Statement of Purpose."

Past Imperfect 14 [2008) | (C) |ISSN 1711-053X| elSSN 1718-4487 
was lost by the civilians and participants of the exercise. The evacuation involved the participation of 1,369 cars and 5,981 individuals. $^{48}$ These numbers were significantly lower than the initial estimation of 40,000 residents. The report optimistically noted the satisfactory level of participant cooperation: "Civil defence workers in the area [CMAA] were able to handle the volume received with very little trouble and could have handled many times the number," which was probably because they were expecting many times the number of individuals than the number that took part in the evacuation. ${ }^{49}$ According to Randy Richmond and Tom Villemaire in their account of Operation "Lifesaver" in Colossal Canadian Failures 2:

Small town after small town reported disappointing numbers of evacuees. In Innisfail 336 people out of 84 cars showed up, out of an expected 3,500. "I think our 218 workers would be a lot happier ... if more evacuees had shown up," said Frank Churchill, chairperson of the civil defence committee. ${ }^{50}$

Richmond and Villemaire went on to different communities and observed the disappointing lack of participants and the early departures of the Calgarians from the receiving communities well before the "all clear" signal which rang at 3:30 in the afternoon.

Sources such as the ACDHQ report indicated an overall effort of civil defence organizations to remain optimistic. Such sources remain useful, however, in their efforts to adamantly emphasize the cooperation of civilians and general homogeneity of the experiment's subjects. The primary concerns of the

${ }^{48}$ Ibid, 19.

${ }^{49} \mathrm{Ibid}$.

${ }^{50}$ Richmond and Villemaire, 95 . 
government lay within these optimistic reflections. Hints of the worries concerning civilian participation were evident in reports in that they were mentioned but quickly discarded. In the CBC documentary, for instance, the announcer noted the level of nonparticipants in the project, commenting that some did not take part on account of highway conditions while others were out of 78| town for the day. He continued on to say, however, that regardless, those who participated in the exercise were enough to make the project worthwhile. Another segment of the $\mathrm{CBC}$ coverage featured police officers surveying the deserted streets: "[...] as an extra precaution the RCMP helped the city police patrol the streets for stragglers." ${ }^{21}$ Following this statement was a scene featuring a police car pulling up beside a solitary man who was walking down the street. No narration followed as a tall red serge-clad RCMP officer stepped out of the car to talk to the "straggler." The civilian's lack of interest in the project, therefore, was briefly shown, mentioned in conjunction with the exercise's success, but never concentrated upon. While disinterest was present, reports and general coverage focussed on the positive and constructive aspects of the exercise.

The third part of the Operation "Lifesaver" report, titled "Lessons and Conclusions," discussed the learning experience through an evaluation and assessment of the successes and failures of Calgary and the receiving communities throughout the exercise. The more beneficial lessons learned through the practice illustrated the effectiveness of the Civil Defence Organization as well as the efficiency of a well prepared public. Less successful were the lessons which illustrated the importance

51 “CBC Newsmagazine,” clip 2, October 9, 1955.

Past Imperfect

14 [2008) | () |ISSN 1711-053X | eISSN 1718-4487 
of traffic control and the warning systems. These problems, interestingly, were almost exclusively technological problems, although there were a few mentions of issues with public courtesy. Another interesting lesson pointed once more to the intense efforts of the civil defence organization and the government to capture the interest and concerns of civilians: "Well planned and repeated publicity is a necessity to attract and hold public |79

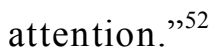

Protests against civil defence, although present in society even as early as the mid 1950s, were separate from the government records detailing the progress of civil defence programs. $^{53}$ The first wave of anti-nuclear protests in Canada occurred at the end of the 1940s and reached a peak in the early 1950 s, following the "launching and consolidation of the Cold War in Canada." 54 The Canadian government during the 1950s basically prohibited anti-nuclear protests and peace movements. According to Whitaker and Marcuse in their study of Canadian Cold War culture and politics, "within certain sectors of Canadian society there were clear signs of a quasi-McCarthyite mentality that did not shrink from using extreme methods, including threats and occasional acts of violence, to intimidate dissenters." 1950 s continued with a lack of interest in the nuclear bomb. Apathy is very different from protest - it is built upon the general

${ }^{52}$ Report on Operation Lifesaver, 21.

${ }^{53}$ The majority of anti-nuclear and anti-bomb protests took place in the second part of the Cold War, during the 1960s, and were often in conjunction with the anti-Vietnam War protests of the era.

${ }^{54}$ Reg Whitaker and Gary Marcuse, Cold War Canada: the Making of a National Insecurity State, 1945-1957 (Toronto: University of Toronto Press, 1994), 364.

${ }^{55}$ Ibid. 
disinterest and disregard for a subject rather than establishing its existence and power through defiance as with protest. In many ways, however, apathy and protest are related in that they show a lack of support for state imposed sanctions.

Some of the best evidence of protests against civil defence measures was found in the materials supporting civil defence 80| through protesting critiques of civil defence theory. The Civil Defence Circular, a monthly Alberta newsletter, attacked Ernest Watkins's article in Saturday Night Review, "Civil Defence a Failure Until It Makes Sense" published in April 1955:

The main problem with this article was his claim with the explosion of a hydrogen bomb over Calgary, half of Alberta's population would wind up dead on account for various winds moving across the province. $C D C$ [Civil Defence Circular] rights this exaggeration with the following facts: with the proper application of Civil Defence procedures citizens would be able to protect themselves from the bomb. Another point the newsletter addresses is the fact that Edmonton did not contain half of Alberta's population and that with the proper protection even the population of Edmonton would be saved: "An ordinary basement properly adapted - is a good protection and can cut radioactivity danger by as much as 90 per cent. A storm shelter, such as a deep root cellar, cave, etc., can give absolute protection., 56

The efforts to maintain a feeling of security from potential attack appeared once again through a persistence of controlled anxiety: there was a threat but it was manageable. Watkins's article apparently countered this view with a disturbing vision of a

${ }^{56}$ Civil Defence Circular 5, no. 2, May 18, 1955, acc. no. 85.368.

Past Imperfect

14 [2008) | (C) |ISSN 1711-053X | elSSN 1718-4487 
radioactive Alberta. The newsletter's effort to rectify the situation presented by Watkins's critique with the simple action of hiding in an "ordinary basement" was inaccurate but reminiscent of the role of propaganda and related attempts to address the apparent critiques to the civil defence program.

The postponement of the Operation "Lifesaver" exercise by a week proved to be telling in terms of civil defence planning and organization. According to the report, the postponement of the exercise on account of weather illustrated the importance of preparation for all conditions in the event of attack:

This in itself emphasized two points. Firstly, in any evacuation plan we must take into consideration the possibility of abnormal weather conditions existing at the time the plan is put into operation. Secondly, plans must be sufficiently flexible to allow the use of alternate roads and highways. ${ }^{57}$

This statement reinforced the prevailing desire to not include the public in any possibility of risk, thus maintaining complete control over the situation, converting potential chaos into calculated reason. Operation "Lifesaver" catered to the desires of both the civilians and the planners. For civilians, the exercise proved that in the event of attack escape and survival was possible - the individual was in charge of his or her fate. For planners, the exercise was portrayed as a success and, despite the poor turn-out, the events went as anticipated.

\section{Conclusion:}

\footnotetext{
${ }^{57}$ Report on Operation Lifesaver, 13.

Past Imperfect 14 [2008) | (C) ISSN 1711-053X| | ISSN 1718-4487
} 
Operation "Lifesaver" was an illustrated product of early Cold War mentality in Canada. The concerns for image, for prestige, and credibility drove the organization and planning of the Calgary evacuation. Planners did not appear concerned with possibilities of subversion and Soviet infiltration: the exercise was widely publicised and the escape routes were clearly defined. The 82| practice, therefore, was indicative of the overall nature of Cold War pride between the East and West, with its anxiety over obscure methods of possible subversion oddly coupled with blatant efforts to show off innovations to the "other side." Operation "Lifesaver" was a small scale expression of western pride which was also evident in the American military tests in the South Pacific when the leaders of the East and West witnessed the explosions together. This method of challenging the other side with preparedness was the essence of the non-combative nature of the Cold War: unwilling to bomb each other, the two superpowers showed off their might through military tests. In the same way, warfare was replaced in the citizen's mind with civil defence practices. This is not to say that there was no fear in terms of exercises like Operation "Lifesaver," but there was something driving the practices beyond simple civilian preparation for attack. There was civic pride. The exercise was perhaps initiated by fear or anxiety, but pride drove the success of the project making it more of an indication of strength than a method of creating an awareness of potential danger to the participating and observing civilians. Through Operation "Lifesaver" a secondary target in a secondary country showed North America that survival from a nuclear attack was not only possible but expected and planned.

\footnotetext{
Past Imperfect

14 [2008) | (C) |ISSN 1711-053X | elSSN 1718-4487
} 
The question remains however, what would Operation "Lifesaver" have been like if the exercise was not presented to the public as a practice but as the "real thing"? This would have been a "true" scientific experiment rather than a vehicle for propaganda. Operation "Lifesaver" was a well-ordered and carefully organized exercise that reflected the concerns of the civil defence organizations and Canadian government during the 1950s. The exercise's purpose was not to test the survival possibilities for civilians through evacuation, but to comfort civilians with the belief and evidence that survival in the face of the greatest destructive power on the planet was indeed possible. Operation "Lifesaver" makes little sense outside of the early Cold War context. It is now seen as a series of blunders and perhaps even farcical in terms of government information given to the public. The apparent loss of Operation "Lifesaver" in the Canadian memory cannot be solely explained by the postponement of the exercise and the subsequent lack of interest but on the mindset of the early Cold War. Operation "Lifesaver" is an illustrative example of the atomic era indicating the government's anxieties and subsequent application of controlled anxiety on the Canadian civilian.

Works Cited

Primary Sources:

Provincial Archives of Alberta, Edmonton:

Civil Defence, "Department of the Environment." Accession no. 72.289.

Civil Defence, “Department of Transportation.” Accession no. 85. 368.

Past Imperfect
14 [2008)| (@) |ISSN 1711-053X| |elSSN 1718-4487 
Emergency Measures Organization, "Executive Council." Accession no. 76.428 .

Television:

"CBC Newsmagazine." 25 November 1956, 3 Dec. 2007 $<$ http://archives.cbc.ca/IDCC-1-71-274-1472/conflict_war/cold_war/> 9 October 1955, 3 Dec. 2007

$<$ http://archives.cbc.ca/IDC-1-71-274-1461/conflict_war/cold_war/clip2>

84

Reports and Commissions:

(No Author). Canada's Civil Defence Policy on Evacuation. (No Publisher), 1957.

Tyhurst, J.S. (MD). Psychological and Social Consequences of Disaster 'What Should the Doctor Do?' Montreal and Ottawa: The Department of Psychology, McGill University and The Defence Research Board, 1954.

\section{Secondary Sources}

Amundson, Michael A., and Scott C. Zeman, ed. Atomic Culture: How We Learned to Stop Worrying and Love the Bomb. Boulder, Colorado: University Press of Colorado, 2004.

Boyer, Paul. By the Bomb's Early Light: American Thought and Culture at the Dawn of the Atomic Age. New York: Pantheon Books, 1985.

Cavell, Richard, ed. Love, Hate, and Fear in Canada's Cold War. Toronto: University of Toronto Press, 2004.

Davis, Tracy C. "Between History and Event: Rehearsing Nuclear War Survival." The Drama Review 46, no. 4 (Winter 2002): 185-190.

Field, Douglas. American Cold War Culture. Edinburgh: Edinburgh University Press, 2005.

Gaddis, John Lewis. The Cold War: A New History. New York: Penguin Press, 2005.

Iacovetta, Franca. "Recipes for Democracy?: Gender, Family, and Making Female Citizens in Cold War Canada." Canadian Women Studies 20, no. 2 (Summer 2000): 12-21.

Kinsman, Gary. "Constructing Gay Men and Lesbians as National Security Risks, 1950-1970.” In Whose National Security?: Canadian State 
Surveillance and the Creation of Enemies, edited by Gary Kinsman, Dieter K. Buse, and Mercedes Steedman. Toronto: Between the Lines, 2000.

Korinek, Valerie J. Roughing it in the Suburbs: Reading Chatelaine Magazine in the Fifties and Sixties. Toronto: University of Toronto Press, 2000.

Lichtman, Sarah A. "Do-It-Yourself Security: Safety, Gender, and the Home Fallout Shelter in Cold War America." Journal of Design History 19, no.1 (2006): 39-40.

McEnaney, Laura. Civil Defence Begins at Home: Militarization Meets Everyday Life in the Fifties. Princeton and Oxford: Princeton University Press, 2000.

May, Elaine Tyler. Homeward Bound: American Families in the Cold War Era. New York: Basic Books, Inc. Publishers, 1988.

Oakes, Guy. The Imaginary War: Civil Defence and American Cold War Culture. New York and Oxford: Oxford University Press, 1994.

Orr, Jackie. Panic Diaries: A Genealogy of Panic Disorder. Durham and London: Duke University Press, 2006.

Richmond, Randy, and Tom Villemaire. Colossal Canadian Failures 2: A Short History of Things That Seemed Like a Good Idea at the Time. Toronto: The Dundurn Group, 2006.

Rose, Kenneth D. One Nation Underground: The Fallout Shelter in American Culture. New York and London: New York University Press, 2001.

Salopek, Marijan. A Survey of Western Canadian Concerns and Fear During the Korean War, Master of Arts Thesis, University of Alberta, 1984.

______. "Western Canadians and Civil Defence: The Korean War Years, 19501953." Prairie Forum: Journal of the Canadian Plains Research Center 14, no. 1 (Spring 1989): 75-88.

Whitaker, Reg, and Gary Marcuse. Cold War Canada: The Making of an Insecurity State, 1945-1957. Toronto: University of Toronto Press, 1994.

Whitaker, Reg, and Steve Hewitt. Canada and the Cold War. Toronto: James Lorimer \& Company Ltd., Publishers, 2003.

Past Imperfect

14 [2008) | (C) ISSN 1711-053X| | ISSN 1718-4487 